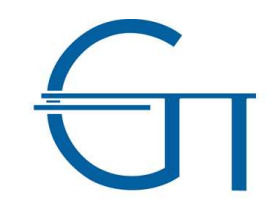

The Hellenic Observatory

The European Institute

\title{
Patterns of spatial association and their persistence across socio-economic indicators: the case of the Greek regions
}

Vassilis Monastiriotis

GreeSE Paper No5

Hellenic Observatory Papers on Greece and Southeast Europe

August 2007 


\section{Table of Contents}

$A B S T R A C T+i i i$

1. Introduction __ 1

2. The regional problem of Greece ___ 3

3. Exploratory spatial data analysis __ 10

4. Patterns of spatial association across aggregates ___ 16

5. Conclusions _ 27

References __ 30

\section{Acknowledgements}

This paper is forthcoming in an edited volume by $\mathrm{H}$. Coccossis and Y. Psycharis titled Modern Perspectives on Regional Economics and Policy in Greece, published by the University of Thessaly Press. Earlier versions of this paper have been presented in the 2005 RSAI (British \& Irish Section) conference in Stratford-upon-Avon, the 2006 International Workshop on Spatial Econometrics and Statistics in Rome and the 2006 ERSA Congress in Volos. I am thankful to participants in these conferences for useful comments and suggestions. I have also benefited from comments by Giuseppe Arbia, Andreas Antoniadis, Badi Baltagi, Eckhard Bode, Yiannis Chorianopoulos, Bernard Fingelton, Ian Gordon, Stamatis Kalogirou, Yiannis Kaplanis and Yiannis Psycharis. Of course, all errors and omissions remain with the author. 


\title{
Patterns of spatial association and their persistence across socio-economic indicators: the case of the Greek regions
}

\author{
Vassilis Monastiriotis ${ }^{\#}$
}

\begin{abstract}
Despite some impressive advances recently in spatial analysis, one important spatial question appears largely overlooked: how spatial dynamics differ across a range of socio-economic indicators. This papers attempts to address this issue, examining data from the prefectures of Greece. It starts with an extensive exploratory spatial data analysis of a range of socio-economic indicators, which helps identify spatial patterns of association characterising the Greek regions. Then, it explores the persistence of spatial clustering across this set of socio-economic indicators through the application of a number of simple statistical tests. Greece presents an interesting case for examination, given its complex nature of spatial disparities and processes, especially in terms of spatial heterogeneity, that are linked in the paper to key aspects of the political and economic development of the country. The derived results are important for Greek regional policy, as they help highlight yet another dimension of the challenges it faces for regional development, but they are also of particular relevance for applied spatial analysis, as they offer new insights in the analysis of spatial processes.
\end{abstract}

Keywords: Greece, ESDA, spatial association, persistence, regional disparities

\footnotetext{
\# Lecturer in the Political Economy of Greece and Southeast Europe, Hellenic Observatory, LSE. Correspondence: Vassilis Monastiriotis, European Institute and Hellenic Observatory, LSE, Houghton Street, WC2A 2AE London. Tel.: +44 (0)20 79556937, Email: v.monastiriotis@1se.ac.uk
} 



\section{Patterns of spatial association and their persistence across socio-economic indicators: the case of the Greek regions}

\section{Introduction}

The question of regional economic performance in Greece is in many respects one of the most challenging questions for national regional policy in the European Union. Although the country exhibits one of the lowest degrees of regional disparities (e.g., regional variation in income levels) amongst the EU15 (Petrakos and Saratsis, 1997; EC, 2005), the Greek regions face a combination of problems of underdevelopment, backwardness, and peripherality, which interact with, and accentuate, the very same problems faced by the country as a whole. Despite an impressive growth performance since the second half of the 1990s and its successful entry into the EMU, Greece is a significant laggard in the EU context, with national income levels well below the EU-15 average and comparable to those of some of the new Member States (for example, Slovenia or Cyprus).

More importantly, in spite of almost twenty years of continuous external aid (through EU's Cohesion and Structural Funds and earlier though the Mediterranean Integrated Programmes), Greece still relies heavily on external support for the updating and expansion of its infrastructure, which is of course crucial not only for economic performance at the national level but also for the development of its most backward regions, a point that was emphatically made in Greece's position during the recent negotiations over the 2007/2013 EU Budget. 
Studies on the issues of peripherality and backwardness in Greece have often highlighted the complex interplay of factors that contribute to accentuate and perpetuate the problems of regional (as well as national) development in the country (see Petrakos and Satarsis, 2000; Konsolas et al, 2002; and Petrakos and Psycharis, 2004). Studies of regional convergence have produced mixed results (Siriopoulos and Asteriou, 1998; Christopoulos and Tsionas, 2004), largely reflecting the heterogeneity of growth processes operating in the country (Alexiadis and Tomkins, 2004). However, studies examining in detail the spatial patterns of association and dependence for a range of socioeconomic aggregates in Greece are extremely limited (for exceptions see Kamarianakis and Prastacos, 2001; Farsari et al, 2001; and Kamarianakis and Kontos, 2004). As a result, an important gap exists in the identification of spatial processes in the country and, more importantly, in the understanding of how such processes operate and how they shape and constrain the developmental potentials at the regional and national levels.

This paper has a dual aim. On the one hand, to provide a systematic exploratory analysis of the patterns of inequality across the Greek regions and, through this, to highlight the complex nature of the economic geography of the country. On the other hand, the paper aims at making a more technical contribution, by exploring ways in which to compare the observed spatial dynamics across variables and measure their persistence. This analysis allows a number of interesting questions to be addressed. First, whether the geographical location of high-performance clusters with positive spillovers (high-high clusters), identified in the exploratory spatial data analysis (ESDA), is consistent across a range of social and economic aggregates. Second, if this consistency is shown to be limited, what are the cross-variable patterns of clustering - in other words, which sets of economic structures (e.g., urbanisation), conditions (e.g., education levels) and outcomes (e.g., unemployment) present similar spatial patterns. Further, what are the implications of the observed dissimilarity of spatial patterns for theory (e.g., if it is known how education impacts on 
productivity, what can be said about the relationship between educational and pure productivity spillovers?) and policy (if spatial processes correlate across interdependent variables, how can policies be best designed to minimise the costs of delivery and avoid the overlapping of interventions).

The next section sets out what the paper describes as the "regional problem of Greece' by reviewing the key developmental problems of the country and examining the regional distribution of a number of social and economic indicators. Section 3 proceeds with the ESDA on this set of socio-economic indicators and briefly evaluates the patterns of clustering, dependence and differentiation that are identified. Section 4 presents the second-level analysis, which seeks to provide comparisons of patterns of spatial association across variables. The final section concludes with some implications for Greek regional policy and some considerations for the method of spatial analysis.

\section{The regional problem of Greece}

In understanding the nature of the 'regional problem of Greece', it is important to highlight the multiplicity of factors influencing and constraining regional economic performance within the national context. Among these factors, the peculiarities of Greece's system of cities, the characteristics of relative national underdevelopment, the patterns of economic and geo-political peripherality, as well as the influence of factors related to the physical geography of the country, are the most important.

System of cities: Greece has an extremely intensive concentration of population around its capital (in Athens and the Attiki region) and a very steep rank-size distribution of urban population, which is largely uncharacteristic of most other EU countries (Petrakos and Brada, 1989). This over-concentration of population in one (or two, if we are to include Thessaloniki, the so-called 'coCapital') urban area interacts negatively with the existence of a small and 
declining rural and semi-urban population and of very low population densities outside the main urban areas. Paradoxically, these are characteristics often seen in developing countries, where core-periphery patterns emerge in the early stages of industrialisation and national economic development.

Characteristics of underdevelopment: Underdevelopment and patterns of coreperiphery characterise Greece also in a more general sense. Greece has a substantial shadow economy; large, inefficient and highly centralised public administration; significantly high structural unemployment; low degrees of industrialisation, relative reliance on agriculture and very few agglomerations outside this sector (Konsolas et al, 2002); poor infrastructure and transportation networks; and income levels persistently below the EU-15 average. These national characteristics impact adversely on the potentials of the most backward regions of the country, not only because national conditions are naturally reflected at the regional level, but primarily because economic backwardness also implies relatively weak spatial economic linkages and diffusion dynamics.

Peripherality: Greece's geo-political position, being isolated from the rest of the EU, and neighbouring countries with which it has a history of tensions and conflict, has accentuated further these characteristics, with the degradation of its transportation infrastructure, the underdevelopment of trade and other economic links ${ }^{1}$, and ultimately the backwardness of Greece's own border regions, which have been particularly hit by this isolation, as the centre has absorbed most international functions, in a typical core-periphery development manner.

Physical geography: The backwardness of the border regions is also linked to the main characteristics of Greece's physical geography, i.e., a combination of mountainous, island, and remote economies. The interaction of Greece's

\footnotetext{
1 Greece's trade statistics show an abruptly closed economy within the context of the EU Single Market. Also underdeveloped are its trade links with its neighbouring Balkan countries (Kaminski and de la Rocha, 2003).
} 
physical landscape with the problems of national development contribute to intensify the problems of peripheral and mountainous regions and of the island economies in the country since, among others, poor physical connectivity does not assist with the diffusion of any economic growth generated at the centre.

All these factors combine to sketch a picture that deviates from simple notions of a singular geography where, for example, a backward and impoverished north co-exists with a wealthier and more dynamic south. Instead, the picture that prevails is that of 'multiple geographies' (Monastiriotis, 2005) manifested in the economic space as a complex pattern of north-south, east-west and coreperiphery inequalities. We examine these complex patterns in the maps presented in Figures 1 and 2. The maps provide a wealth of information but their treatment here is selective, as the main objective is simply to depict the various patterns exhibited by Greece's economic geography rather than to discuss in detail the geographical distribution of specific socio-economic aggregates.

Key aspects of these complex patterns can be highlighted in the following. As is depicted in Figure 1, productivity and incomes are higher in and around the two main conurbations (Athens and Thessaloniki), in Kozani in the northwest (which hosts the largest energy production site in the country) and in the southeast Aegean (which benefits significantly from international tourism). However, earnings do not follow the same geography and high values appear to be more localised along the Patras-Athens-Volos axis and in Cyclades in the Aegean.

In terms of employment outcomes (second row of maps), the geography is in many respects markedly different. The two main urban centres again stand out, with high employment concentrations, but employment seems to follow largely a southeast-northwest dichotomy. Interestingly, although some border regions in the north face acute problems of unemployment (related to the substantial relocation of mainly small businesses across the borders; Labrianidis, 2003), 
youth unemployment, which is the main source of structural unemployment in the country (Lyberaki, 2005), is most notably a problem in the rural areas of western and north-western Greece.

Figure 1. Economic performance in the Greek Prefectures

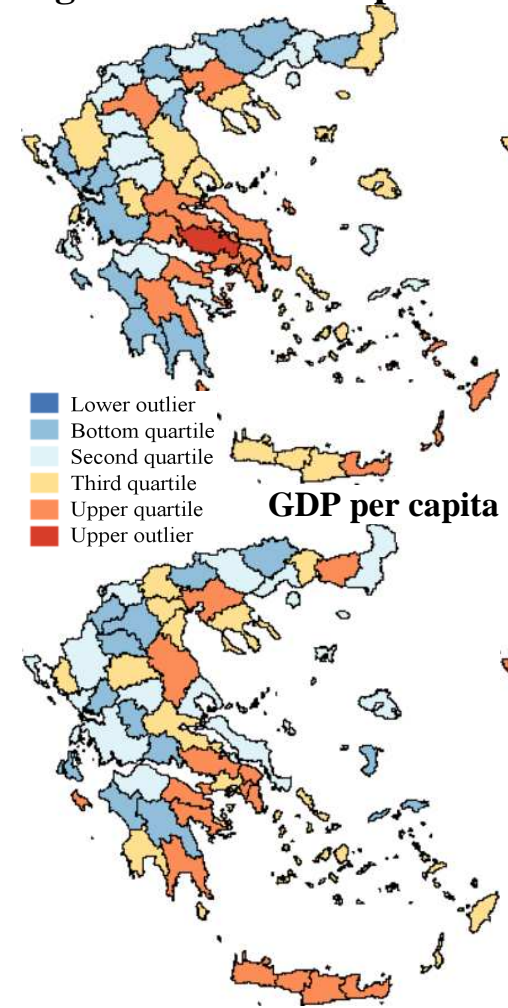

Employment/Population
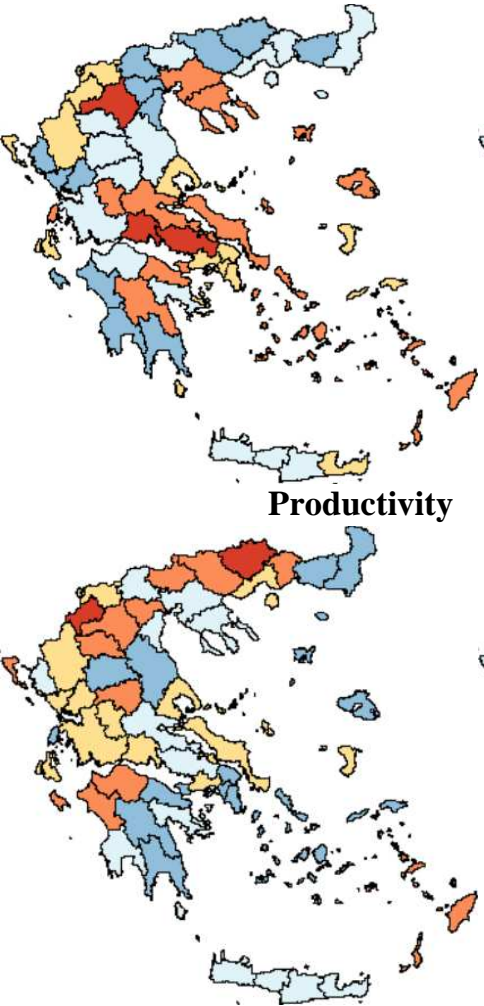

Unemployment rate
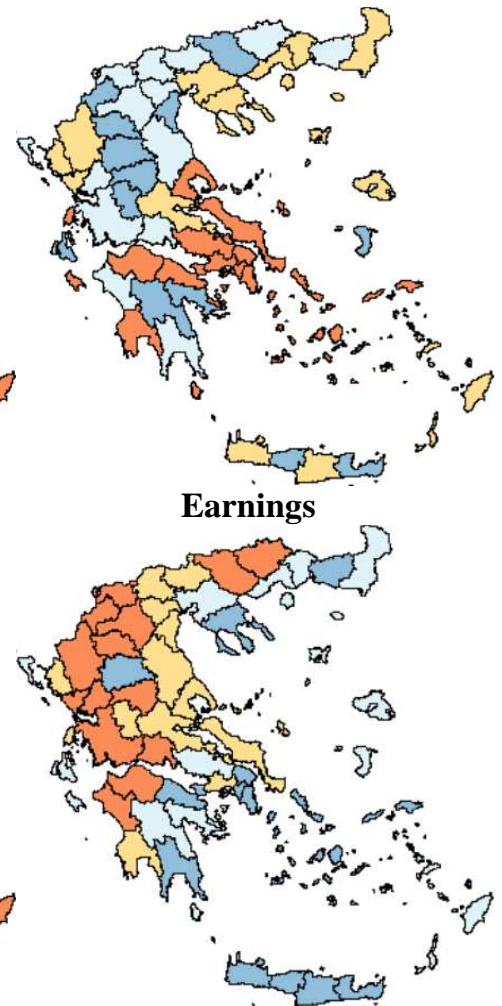

Youth unemployment Notes: Data from the Greek National Statistical Service; quartiles and outliers produced in GeoDa.

Nevertheless, despite the adverse picture with regards to unemployment, many of these areas have strong concentrations of skilled employment (either manual or non-manual; or both) and notably low shares of unskilled employment (Figure 2). In fact, the distribution of unskilled employment seems to follow more closely the geographical pattern of earnings, with high values concentrating mainly around the two main urban agglomerations of the country. 
Figure 2. Employment compositions in the Greek Prefectures

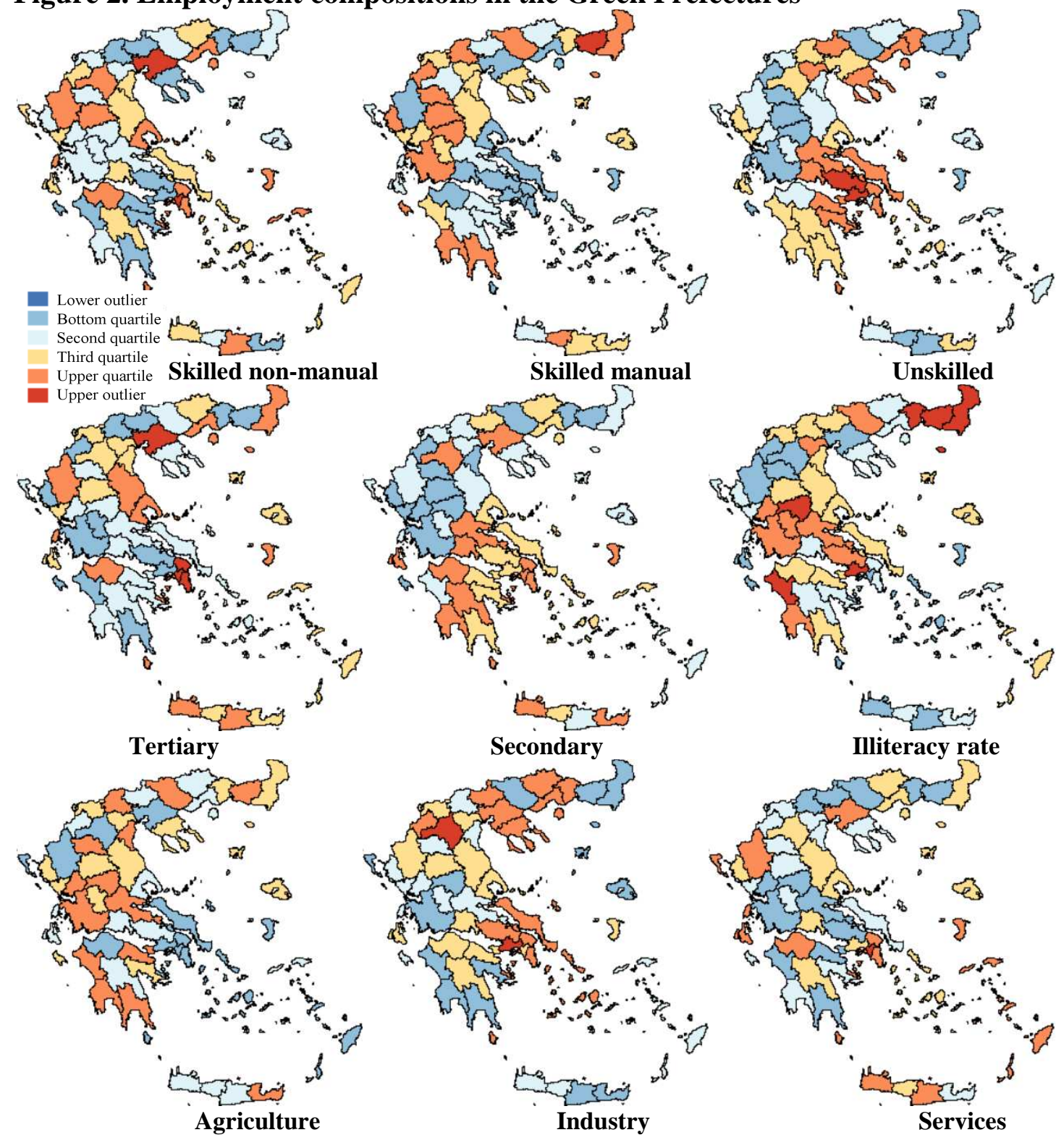

Notes: Data from the Greek National Statistical Service; quartiles and outliers produced in GeoDa.

Also strongly concentrated around these two areas is the working-age population with a university degree (tertiary education), although this probably reflects the low mobility of university graduates, as high values are observed effectively in all areas with large universities (Patras, Giannena, Thessaly, Crete). For secondary education, however, a clearer north-south pattern can be seen, with large parts of western and mainland Greece fairing well-below average. Interestingly, the geography of illiteracy in the country follows a rather distinctive distribution, apparently reflecting more historical (i.e., the 
location of ethnic minorities) and socio-political (e.g., rurality, deprivation) than educational characteristics. Similarly, such exogenous characteristics are also reflected in the geography of economic activity (last row of maps in Figure 2). Industry is mainly concentrated in and around the two main conurbations, as well as in Kozani (power generation) and the manufacturing enclave of Eastern Macedonia. Most parts of central Greece and southwest Peloponnese specialise in agriculture, while services are mainly concentrated in the largest cities and in the islands, reflecting the importance of tourism for these economies.

This review of the geographical distribution of socio-economic aggregates in Greece, albeit somewhat sketchy, highlights well the picture of 'multiple geographies' observed in the country. Besides this picture, another interesting feature of Greek regional disparities relates to the size of these disparities across types of socio-economic aggregates. As already mentioned, regional income disparities in Greece are relatively small, compared to other EU or OECD countries. However, regional disparities in a host of other indicators, besides incomes, are sizeable. In Figure 3 we have split a set of 25 socioeconomic indicators to four groups, representing characteristics more closely related to regional structures, the regional labour force, the regional labour markets, and regional incomes. The first two categories reflect particularly specialisations and/or regional comparative advantages, while the latter two correspond to economic outcomes / performance indicators. It can be seen that inequalities in both outcome categories (incomes and the labour market, although GDP pc growth is an outlier here) are relatively small, especially so in terms of inactivity, employment participation and earnings. Also minor are the disparities in terms of labour force characteristics (with the exception of illiteracy, which is heavily influenced by the presence of a Muslim minority in Thrace), and despite the strong geographical patterns for these variables depicted in Figures 1 and 2. 
Figure 3. Regional disparities in main socio-economic aggregates

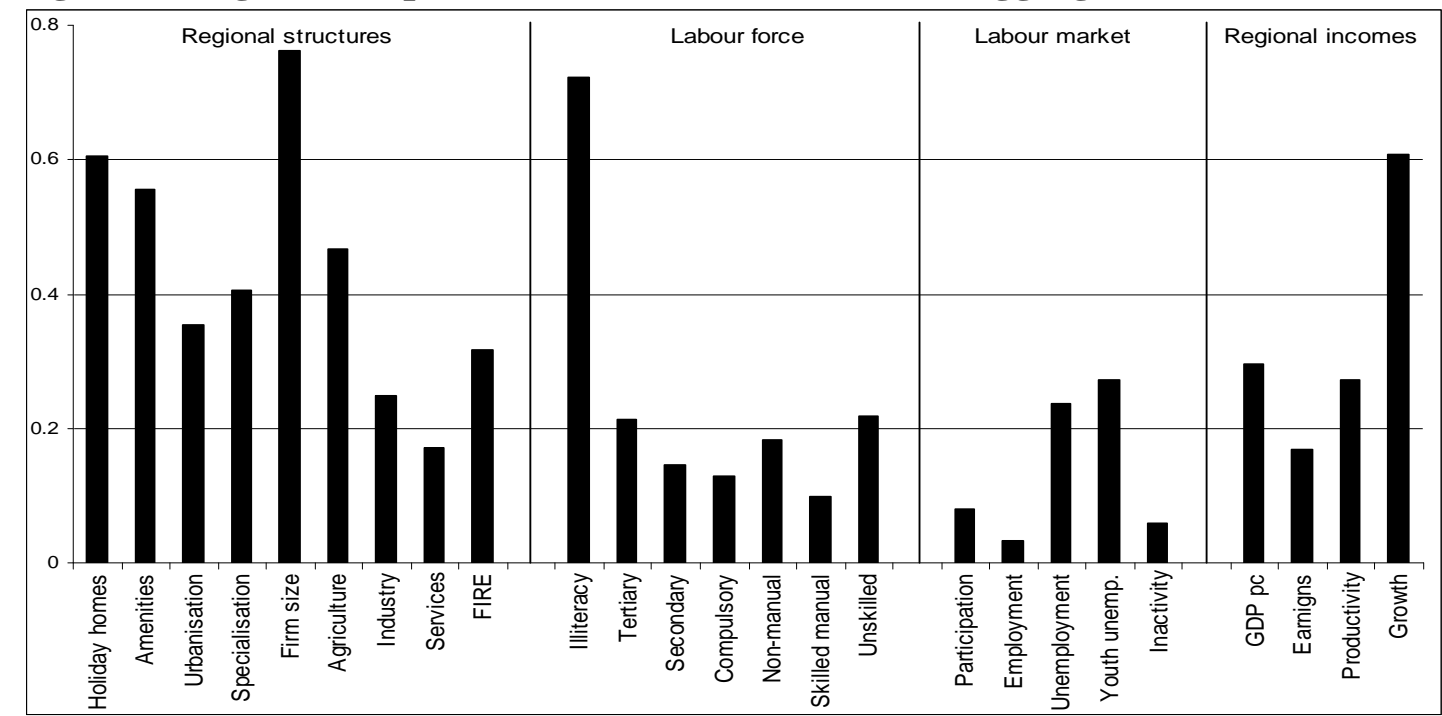

Notes: Coefficients of variation across the Prefectures of Greece. Data have been provided by the National Statistical Service of Greece and refer to 2001 (1995-2001 for growth rates).

On the other hand, regional inequalities in terms of regional structures appear sizeable. ${ }^{2}$ Although in conjunction these characteristics would seem to suggest that redistribution and spatial equilibrating forces may operate well in the Greek economy (i.e., the relative homogeneity, across regions, of earnings, productivities and unemployment rates), inversely, the patterns depicted in Figure 3 can be seen as highlighting the structural character of regional differentiation observed in the country. Urbanisation rates, housing amenities (which include access to electricity and sewage), patterns of industrial specialisation and, most notably, firm sizes (measured by average firm sales) exhibit a significant degree of variation. For policy, this suggests that interventions to enhance social and economic cohesion across space require much more than redistribution (e.g., income support or unemployment benefits) and market liberalisation policies (e.g., policies to increase labour mobility and wage flexibility).

To summarise, although regional disparities in Greece are not as acute as in other parts of the EU, the nature of regional disparities and regional

\footnotetext{
${ }^{2}$ As noted earlier, also sizeable is the variation in growth performance across the Greek regions. In this respect, income growth can also be seen as an additional characteristic of regional structures.
} 
backwardness in Greece appears particularly complex and thus probably more challenging intellectually than in other cases. In fact, one can simply compare the complexity of these patterns to the almost natural-law-like pattern of inequality in the UK (the infamous north-south divide; Blackaby and Murphy, 1995; Duranton and Monastiriotis, 2002), the three macro-regions in Italy (north, south, and third Italy; Poti and Basile, 2000), the various industrial and other 'belts' and 'pentagons' in the EU and the USA (Ottaviano and Puga, 1997; EC, 1999), or even the emerging patterns of east-west inequality in the post-transition economies of Central and Eastern Europe (Petrakos, 2001), in order to highlight the peculiarity of Greece's 'regional problem'. Given this peculiarity, it appears important to examine further the nature of spatial linkages across the Greek regions and to explore to what extent these have any systematic pattern that persists across measures of socio-economic conditions and performance.

\section{Exploratory spatial data analysis}

The patterns of regional disparity highlighted by the visual inspection of the geographical distribution of socio-economic aggregates in Greece suggest a multiplicity of spatial processes operating in the country. This section performs an exploratory spatial data analysis ${ }^{3}$ for the main of these socio-economic variables in order to formally examine the extent and nature of such spatial processes. Specifically, this analysis examines formally the extent of spatial clustering aiming at exploring the geography of three main spatial processes: spatial diffusion (positive spatial autocorrelation), spatial competition (negative spatial autocorrelation) and spatial heterogeneity (differences in spatial regimes). We start by first considering the extent of global spatial association,

\footnotetext{
${ }^{3}$ For an explanation of the logic and method of exploratory spatial data analysis see Anselin (1988 and especially 1995). For a quick reference on the technique see Luc Anselin's GeoDa Workbook at the Centre for Spatially Integrated Social Science (https://www.geoda.uiuc.edu/pdf/geodaworkbook.pdf).
} 
as depicted in Table 1 (Moran's I statistics; for reference, we also include the coefficients of variation presented in Figure 3).

Table 1. Disparities and spatial dependence: main socio-economic aggregates

\begin{tabular}{l|cc||l|cc}
\hline \multicolumn{1}{c|}{ Indicator } & CoV & Moran I & Indicator & CoV & Moran I \\
\hline GDP pc & 0.296 & 0.24 & Participation & 0.079 & 0.27 \\
Earnings & 0.168 & 0.32 & Employment & 0.033 & 0.18 \\
Productivity & 0.272 & 0.21 & Unemployment & 0.236 & 0.18 \\
Growth & 0.608 & 0.11 & Youth unempl. & 0.272 & 0.36 \\
Amenities & 0.555 & 0.20 & Inactivity & 0.060 & 0.18 \\
Urbanisation & 0.353 & 0.35 & Illiteracy & 0.723 & 0.43 \\
Specialisation & 0.406 & -0.01 & Tertiary & 0.213 & 0.04 \\
Turnover & 0.763 & 0.12 & Secondary & 0.145 & 0.32 \\
Agriculture & 0.466 & 0.16 & Compulsory & 0.128 & 0.17 \\
Industry & 0.250 & 0.30 & Non-manual & 0.184 & -0.04 \\
Services & 0.172 & 0.13 & Skilled manual & 0.100 & 0.29 \\
FIRE & 0.318 & 0.36 & Unskilled & 0.218 & 0.43 \\
\hline
\end{tabular}

Notes: Moran I statistics calculated in GeoDa based on a simple queen contiguity criterion. Contiguity for island regions has been assigned on the basis of their administrative borders. Alternative contiguity criteria (nearest neighbours and distance thresholds) produced qualitatively very similar results.

As can be seen, in all but two cases the evidence suggests the presence of positive spatial autocorrelation, which appears to be statistically significant in virtually all cases. ${ }^{4}$ Thus, at the global scale, as one would expect, socioeconomic outcomes appear clustered and/or positively associated in space. Further, although in some cases (e.g., GDP growth) the degree of association is not particularly strong, in most cases spatial dependence is sizeable. For example, by comparison, spatial dependence of wages across the British counties is less than two thirds of that for earnings across the Greek prefectures (both of which are of a similar number in both countries) (Monastiriotis, 2006). As is also suggested by the visual inspection (Figures 1 and 2), much stronger is the spatial clustering for variables like unskilled employment and youth unemployment. In what follows we concentrate on these and a selection of other key socio-economic variables (inactivity, housing amenities, productivity,

\footnotetext{
${ }^{4}$ For the variables with the lowest positive scores for Moran's I (output growth, firm size, services, etc) the statistics are consistently significant at the $10 \%$ level. For the highest scores p-values are below $1 \%$.
} 
employment shares of industry and business services, skilled manual employment, and secondary education) to economise on space - the results are indicative also of the patterns of the other variables.

Figure 4 presents the geography of local spatial association through a number of LISA maps. ${ }^{5}$ The three rows correspond to labour force characteristics, economic / labour market outcomes, and regional structures, respectively. Across all measures, as expected, some strong spatial patterns of clustering are observed. For secondary education there is a high-value cluster around the Capital and a low-value cluster in the northwest. Similar is the pattern of clustering in the case of unskilled employment (but, interestingly, not for the prefecture of Athens). For this variable there is additional evidence for relative clustering of low values in the eastern-most and island parts of the country and of high values around Thessaloniki, but these clusters are not statistically significant. Regarding skilled employment, the picture is naturally reversed, although this time clustering appears weaker and the only statistically significant cluster is that of low values in the broader functional region of Athens. As was highlighted earlier, these patterns seem to confine the whole complexity of regional disparities in Greece, showing signs of all forms of eastwest, north-south, urban-rural and core-periphery inequality.

The picture regarding the performance indicators (second row of maps) is somewhat simpler, as it mainly picks up the underperforming northwest crescent of mainland Greece. A high-concentration cluster of inactivity and youth unemployment is located in the western and northern periphery of the country. The same areas are largely areas of low productivity, but in this case there is much greater variation and thus clustering is not statistically significant. In contrast, a strong high-productivity cluster is located north of

\footnotetext{
${ }^{5}$ To avoid missing out on important information (albeit not always statistically significant, strictly speaking), we deviate from common practice and map all local Moran I values, irrespective of their statistical significance. Where relevant, we comment on the issue of statistical significance in the text.
} 
Attiki. ${ }^{6}$ In this context, the southern Aegean islands appear to belong to this high-productivity cluster, mainly due to their function as a tourist destination for the high-concentration high-income population of Athens (which hosts a third of the total population of the country).

Figure 4. LISA maps of key socio-economic indicators

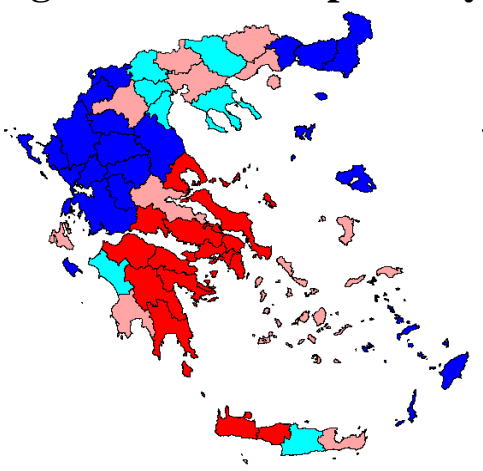

Secondary education

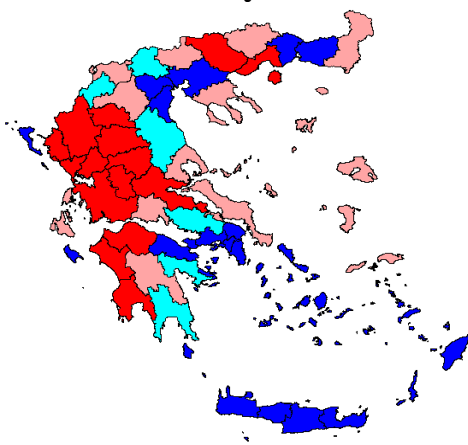

Inactivity

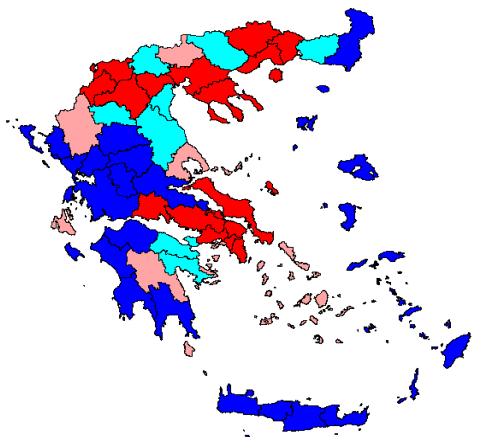

Industry

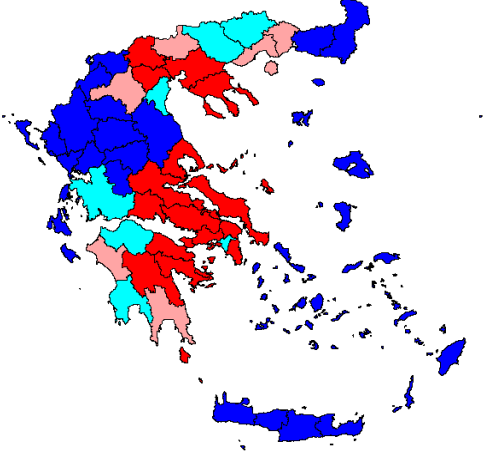

Unskilled

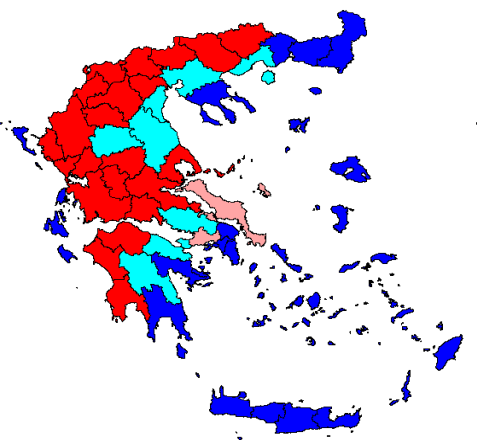

Youth unemployment

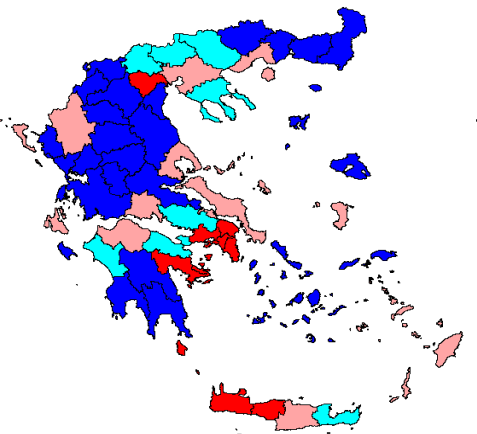

Business services (FIRE)

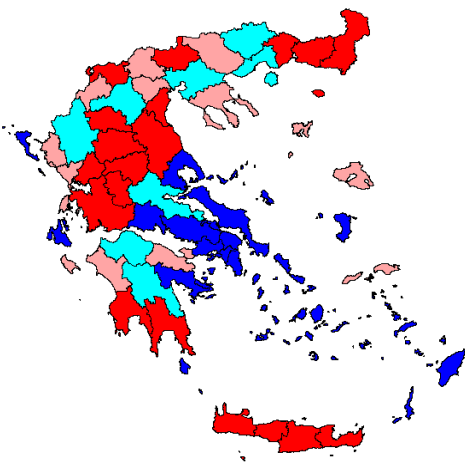

Skilled manual

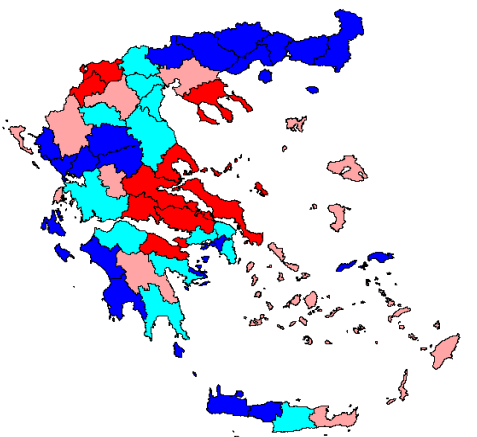

Productivity

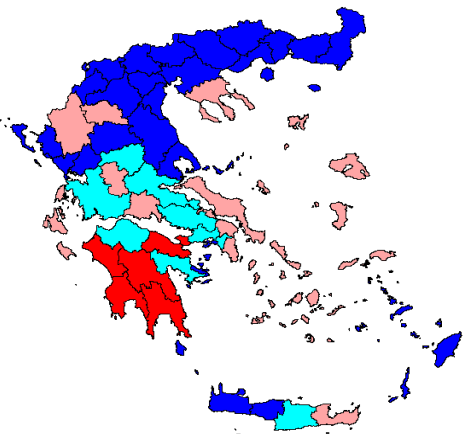

Housing amenities

Notes: Colours correspond to the standard LISA clusters: HH (red), HL (pink), LH (light blue), and LL (dark blue). LISA values calculated in GeoDa on a simple queen contiguity criterion.

\footnotetext{
${ }^{6}$ The non-inclusion of Attiki is partly a statistical artefact owing to the measurement of GDP at the workplace and of population at the place of residence - in the case of earnings this cluster extends southwards to include the Capital.
} 
Finally, in the case of regional structures, the spatial patterns of inequality appear again more mixed. Industrial employment shows a combination of a north-south and a core-periphery pattern: it is mostly concentrated in the north and in the broader functional region of Athens, while the western and island parts of the country form a clear periphery. Interestingly, however, only the Athens cluster is statistically significant, while all other statistically significant LISAs are found in (low-industry) agricultural enclaves in the north. As should be expected, business services are much more concentrated in fewer and smaller centres, mainly around the largest conurbations of the country. Of the high-value clusters, the one servicing Thessaloniki in the north and the one servicing Crete in the south are not statistically significant. The stark concentration of low values in central and western Greece produces one statistically significant cluster of two regions (Arta and Karditsa), while the low-value concentration in the northeast is also statistically significant. Lastly, the spatial patterns depicted in the case of housing amenities (proxied here by the share of homes not connected to central sewage facilities) seems to reflect more than anything else the political history of the country. The northern parts of the country, which were annexed to Greece only one century ago, form a strong cluster of low values (high amenities), while the distribution of amenities changes gradually as we move further south along mainland Greece, resulting in a significant high-value cluster in central Peloponnese. ${ }^{7}$

Table 2. Spatial heterogeneity in main socio-economic aggregates

\begin{tabular}{l|ccccc}
\hline \multicolumn{1}{c|}{ Indicator } & Core & North & West & Aegean & Periphery \\
\hline Secondary education & $0.0559^{*}$ & $-0.0308^{*}$ & $-0.0344^{*}$ & 0.0333 & $-0.0582^{*}$ \\
Unskilled employment & $0.0526^{*}$ & -0.0106 & -0.0197 & -0.0181 & $-0.0272^{*}$ \\
Skilled manual empl. & $-0.0754^{*}$ & $0.0337^{*}$ & 0.0230 & 0.0028 & $0.0504^{*}$ \\
Inactivity rate & -0.0171 & 0.0006 & 0.0188 & -0.0069 & 0.0175 \\
Youth unemployment & -0.0076 & 0.0070 & 0.0094 & $-0.0189 *$ & $0.0146^{*}$ \\
Productivity & $8.3884^{*}$ & -3.3598 & -3.9762 & 1.4775 & $-6.5567 *$ \\
Industry share & $0.0494^{*}$ & $0.0307^{*}$ & $-0.0436^{*}$ & -0.0286 & -0.0126 \\
Business services & $0.0197^{*}$ & -0.0068 & -0.0085 & -0.0005 & $-0.0136^{*}$ \\
Housing dis-amenities & 0.0398 & $-0.2142^{*}$ & $0.2460 *$ & -0.1252 & 0.0353 \\
\hline
\end{tabular}

Notes: Differences of means for pair-wise comparisons of means between the named sub-samples (e.g., 'core', 'north', etc) and the rest of the country. Asterisks (*) show significance at the 5\% level.

\footnotetext{
${ }^{7}$ The high values in the Aegean islands are in accordance to the old-new Greece distinction employed here, but arguably are mainly due to their geomorphology than to strictly historical political reasons.
} 
Although the analysis conducted thus far clearly indicates the strong presence of clustering and of macro-geographical patterns (core-periphery, east-west, etc), it is important to take the analysis one step further and try to establish whether and to what extent the identified patters correspond to some form of spatial heterogeneity consistent with the presence of distinctive spatial regimes. A straightforward way to do this is to examine the changes in the distribution of given characteristics (socio-economic variables) as one moves along different spatial regimes. Instead of examining these distributions by visual inspection of their histograms for different sub-samples of the data, in Table 2 we present a set of comparisons of means (t-tests for the equality of means) for a number of spatial groups (regimes) selected in an ad hoc fashion, to correspond to the identified geographies of the country. Thus, one group was identified as the core, consisting of the regions in the broader functional region of Athens. The north was designed to include all regions of northern Greece (West, Central, and East Macedonia and Thrace). The west includes the regions of Ipeiros and Western Mainland Greece, the Ionean islands and the western part of Peloponnese, while the Aegean group includes the islands of Cyclades, Dodekanese and Crete. Finally, the group labelled periphery is a combination of the west and north groups.

Interestingly, on a first glance the patterns depicted in Table 2 do not seem to offer strong support to the assumption of spatial heterogeneity along the dimensions discussed earlier. The west-east and north-south generalisations produce significant differences only in three or four of the nine cases considered in total and mainly in the cases of secondary education, industrial employment and housing disamenities. Nevertheless, at a closer inspection, combined these generalisations (last column) produce significant differences also in the cases of occupational employment shares (manual and unskilled), youth unemployment, labour productivity and business services. Thus, overall, it is only for the case of the inactivity rate that we fail to find a meaningful regional grouping that would capture the heterogeneity in the distribution of 
this variable across space. As expected, the results for the core group (first column) present virtually the inverse picture of what is obtained for the periphery. On the other hand, the distinction of an Aegean group does not seem to be particularly relevant here.

These results again confirm the main observation made earlier, about the existence in Greece of a set of 'multiple geographies' that combine a set of characteristics of core-periphery, north-south and east-west inequality. Having established and analysed this geographical characteristic, we now turn to the ultimate objective of the present study, namely the examination of the persistence of patterns of spatial association across sets of socio-economic indicators.

\section{Patterns of spatial association across aggregates}

From a theoretical perspective, it is not clear why or to what extent spatial processes should correlate across variables. In technical terms, examining similarity of spatial processes across variables can be seen as a means of testing the robustness of a given spatial analysis exercise. For example, confidence in the results obtained for the analysis of spatial patterns of household incomes would be strengthened if it were found that similar are the patterns obtained for incomes at the individual level. Alternatively, this type of comparison of spatial patterns could be seen as a means of testing for the spatial influence of unmeasured characteristics. Keeping with the example of incomes, comparison of the spatial dynamics (autocorrelation, clustering, etc) of earned (pre-tax) and disposable incomes (after taxes and transfers) could help reveal the redistributive or otherwise role of fiscal policy. ${ }^{8}$ Finally, and perhaps more obviously, comparison of spatial dynamics could facilitate an examination of

\footnotetext{
${ }^{8}$ In this example, it would be expected that the spatial patterns of disposable incomes would deviate more from those of earned incomes the more egalitarian was the system of fiscal transfers in a given country - for any given initial geographical distribution of incomes.
} 
changes over time of the spatial processes that operate in the context of the geographical distribution of a given variable. For example, one could examine the persistence over time of a particular spatial pattern by comparing the results of the spatial analysis of household incomes between two reasonably distanced periods (say, five or ten years).

Nevertheless, the performance of such comparisons has an additional value which extents to the field of theory. Assume that an economy is characterised by increasing returns to scale in the production due to the presence of (endogenous) growth-enhancing human capital accumulation. Further assume that output growth exhibits a pattern of positive spatial autocorrelation, reflecting the clustering of positive and adverse outcomes in different locations. Naturally, it is interesting to explore to what extent this can be due to some mechanistic process relating to output growth (for example, productivity spillovers through competition and imitation effects), or one that relates specifically to human capital accumulation (knowledge spillovers through human interaction - see Lucas, 1988), or rather to a more deterministic mechanism, whereby spatial concentration of human capital directly raises output in neighbouring locations (for instance, due to knowledge-related supply linkages).

In the case of the current example, where an underlying structural model can be easily specified (e.g., local growth can be made a function of local human capital accumulation and of the spatially-weighted values of growth and human capital in neighbouring areas), spatial econometric analysis (in the form of a cross-lag spatially autoregressive model) could possibly help shed light on the question of determination of local growth effects. ${ }^{9}$ In cases where a structural model is difficult to specify, a more fruitful strategy would be to try and test directly the similarity of spatial patterns across a range of variables.

\footnotetext{
${ }^{9}$ Nevertheless, in this case estimation problems would arise, as the two spatially weighted variables would be collinear, the more so the stronger the link is between human capital accumulation and output growth.
} 
More generally, the theoretical value of such comparisons lies with their ability to show how appropriate is it to generalise from observed spatial patterns in order to draw more universal inferences about the spatial dynamics that connect a given set of local economies. The importance of such an approach was first highlighted over twenty years ago, before the recent development of the methods of spatial econometric analysis (Wartenberg, 1985). Its relevance, however, remains today, despite the advances of spatial econometrics. For example, a recent thread in Openspace, the user support mailing list of GeoDa, reflected exactly this need, to examine in a parametric way (besides the visual inspection) how spatial patterns correlate across a range of variables. ${ }^{10}$

Various parts of relevant literatures offer in fact a number of solutions to this problem. In the GIS literature, a number of methods for map comparisons have been developed that provide parametric tests for the similarity of spatial patterns across pairs of variables (e.g., the Kappa statistic; see Hagen, 2003). Although such methods are the obvious way of making before/after comparisons of (quasi-)continuous spatial patterns (e.g., examining deforestation), they are less relevant for area-level socioeconomic analyses where spatial variations are discrete and changes/differences are more complex. ${ }^{11}$

Two other techniques originate from the much earlier literature of spatial statistics. Sokal and Menozzi (1982) applied cluster analysis on a set of univariate Moran's I statistics to identify clusters of variables with similar spatial patterns. This technique is more relevant in cases where the interest is in identifying groups of variables rather than in simply comparing the persistence of spatial patterns across variables. Somewhat similar is the case of the approach proposed by Wartenberg (1985), which uses principal components analysis to produce a matrix of multivariate Moran Is, which were subsequently

\footnotetext{
10 See the thread titled 'Comparing LISA Maps' (posted on 24 January 2006) at http://sal.uiuc.edu/pipermail/openspace/2006-January/000677.html

${ }^{11}$ For the case of discrete versus continuous space, the problem is that map comparison methods are based on pixel-by-pixel comparisons of raster maps. Thus, application of the method to area-level variables penalises small areas and overestimates the patterns found for larger geographical areas.
} 
used to summarise the spatial patterns observed in a given multidimensional dataset. Again, in this case, emphasis was placed on summarising the spatial patterns (i.e., grouping the variables into clusters) rather than measuring the degree of similarity of these patterns per se.

In this paper the interest is in fact on the latter. For this reason we favour a more straightforward application for the analysis of similarity of spatial patterns based on two sets of simple tests of association, namely the Pearson correlation coefficient and the chi-square test for independence. We complement this analysis with a version of the principal components methodology proposed by Wartenberg (1985) in order to examine the stability and robustness of the correlation and chi-square results.

More specifically, our analysis in this section is in three steps. First we perform a full set of correlation analyses on the LISAs (local Moran I's) obtained for all the socio-economic indicators in our dataset. As with the mapping of the LISAs earlier, we apply a more relaxed criterion of significance (in this case we assume that the LISA statistic takes the value of zero if its associated p-value is greater than 0.333 ) because we are interested in obtaining information from as wide a range of spatial patterns as possible, irrespective of whether they meet the strict criteria of statistical significance associated with hypothesis testing. Secondly, for each pair of socio-economic variables, we perform a chi-square analysis of independence on the LISA clusters derived from the ESDA of the previous section. ${ }^{12}$ Finally, we return to the local Moran Is and apply a number of alternative principal components analyses (including un-rotated, rotated, and non-orthogonal components), in order to identify the main components that best summarise the patterns of spatial association observed in our data.

\footnotetext{
12 Dall'erba (2003) performs a similar analysis to examine the coincidence between clustering of initial-period GDP per capita and of long-run growth performance for 145 European regions. This is to our knowledge the only regional economic study to perform such a cross-variables comparison of spatial patterns.
} 
Table 3. Similarity between spatial patterns: correlation analysis

\begin{tabular}{|c|c|c|c|c|c|c|c|c|c|c|c|c|c|c|c|c|c|c|c|c|c|}
\hline & & egi & na & inc & & & & gio & nal & strı & ctuı & & & orr & nar & ket & & abo & $\mathbf{u r}$ & orc & \\
\hline & 1 & 2 & 3 & 4 & 5 & 6 & 7 & 8 & 9 & 10 & 11 & 12 & 13 & 14 & 15 & 16 & 17 & 18 & 19 & 20 & 21 \\
\hline GDP & & & & & & & & & $*$ & & $*$ & & & & & & $*$ & & $*$ & $*$ & \\
\hline GDP pc & & & * & $*$ & $*$ & & & & $*$ & & & * & & & & & & & & $*$ & $*$ \\
\hline Earnings & & * & & $*$ & $*$ & & & $*$ & & & & $*$ & & & & & & & & $*$ & $*$ \\
\hline Productivity & & * & * & & * & & & & & & & & & & & & & & & & $*$ \\
\hline Turnover & & $*$ & $*$ & $*$ & & & & & & & & $*$ & & & & & & & & & $*$ \\
\hline Growth & & & & & & & & & & & & & & & & & & & & & \\
\hline Holiday housing & & & & & & & & & & & & & & & & & & & $*$ & & \\
\hline Amenities & & & * & & & & & & & & & $*$ & & $*$ & & & & & & & \\
\hline Urbanisation & $*$ & $*$ & & & & & & & & & $*$ & & & & & & $*$ & & & $*$ & \\
\hline Specialisation & & & & & & & & & & & $*$ & & & & & & $*$ & & $*$ & & \\
\hline Agri/Serv/FIRE & $*$ & & & & & & & & $*$ & $*$ & & & & & & & $*$ & & $*$ & $*$ & \\
\hline Industry & & $*$ & $*$ & & $*$ & & & $*$ & & & & & $*$ & & & $*$ & & & & & $*$ \\
\hline Participation & & & & & & & & & & & & * & & & $*$ & $*$ & & & & & \\
\hline Unemployment & & & & & & & & $*$ & & & & & & & $*$ & & & & & & \\
\hline Youth unempl. & & & & & & & & & & & & & & & & & & & & & \\
\hline Inactivity & & & & & & & & & & & & $*$ & $*$ & & & & & & & & \\
\hline Education & $*$ & & & & & & & & $*$ & $*$ & $*$ & & & & & & & & $*$ & $*$ & \\
\hline Illiteracy & & & & & & & & & & & & & & & & & & & & & \\
\hline Skilled & $*$ & & & & & & $*$ & & & $*$ & $*$ & & & & & & $*$ & & & $*$ & \\
\hline Skilled manual & $*$ & * & * & & & & & & $*$ & & $*$ & & & & & & $*$ & & $*$ & & \\
\hline Unskilled & & $*$ & * & $*$ & $*$ & & & & & & & $*$ & & & & & & & & & \\
\hline
\end{tabular}

Notes: Asterisks indicate correlation coefficients significant at $10 \%$.

Thus, our correlation and principal components analyses try to identify groups of variables for which the local patterns of spatial autocorrelation behave in a similar fashion. In contrast to the principal components approach, however, the correlation analysis does not produce summary measures (i.e., principal components or clusters) and thus allows for two variables to have a common spatial pattern with a third variable but not between them. On the other hand, the chi-square analysis aims at measuring the persistence of classification, for each location, as a low-low, high-high, or other cluster. Thus, rather than examining similarities in the extent of spatial dependence, as with the correlation and principal components analyses, the chi-square analysis examines similarities in the type of spatial dependence of each area. Tables 3-5 present a summary of results from the three sets of analysis. 
As can be seen from the results of the correlation and chi-square analyses, patterns of spatial association show largely little consistency across socioeconomic aggregates. Especially in the case of the correlation analysis (Table 3), persistence of spatial patterns characterises mainly the aggregates related to (components of) regional incomes and to a lesser degree labour market outcomes. In these cases, the results can be best seen as a robustness test, whereby spatial patterns appear consistent irrespective of the measure of incomes (GDP pc, productivity, earnings) or employment outcomes (inactivity, employment participation, etc) or as a confirmation of a known theoretical relationship (link between level of development and firm turnover). Correlation of aggregates within the other two groups of variables described above as measures of regional specialisations and comparative advantage (i.e., regional structures and labour force characteristics) appears much weaker. Spatial patterns of clustering in terms of urbanisation and agricultural and service employment are similar, as one would expect due to the urban/rural nature of these activities. Similarly, high levels of education and skilled employment also have common patterns of local spatial association; but this does not generalise to low levels of education and unskilled employment, neither is there an inverse picture of the revealed spatial patterns between advantageous and less competitive labour force characteristics.

Surprisingly, the spatial patterns observed for labour market outcomes do not appear to link to the spatial dynamics of any other socio-economic aggregate, with the counter-intuitive implication that clusters of, say, unemployment and inactivity do not overlap with clusters of low earnings, educational deprivation, or any particular sectoral specialisations (and, perhaps more importantly, neither do their overlap with one another). On the other hand, for regional incomes some weak correlations with spatial patterns of occupational and sectoral characteristics are found, as is the case for regional structures and some labour force characteristics. The latter are again only weakly correlated with 
regional incomes (especially unskilled employment) and structures (especially education).

Table 4. Similarity between spatial patterns: chi-square analysis

\begin{tabular}{|c|c|c|c|c|c|c|c|c|c|c|c|c|c|c|c|c|c|c|c|c|c|}
\hline & \multicolumn{6}{|c|}{ Regional incomes } & \multicolumn{6}{|c|}{ Regional structure } & \multicolumn{4}{|c|}{ Labor market } & \multicolumn{5}{|c|}{ Labour force } \\
\hline & 1 & 2 & 3 & 4 & 5 & 6 & 7 & 8 & 9 & 10 & 11 & 12 & 13 & 14 & 15 & 16 & 17 & 18 & 19 & 20 & 21 \\
\hline GDP & & * & * & & * & & & & * & & * & & * & & * & * & * & * & * & * & * \\
\hline GDP pc & * & & * & * & * & & * & & * & & * & & * & * & & * & * & & & * & * \\
\hline Earnings & * & & & * & * & & * & * & * & * & * & & & & & & * & & * & * & * \\
\hline Productivity & & * & * & & * & & * & * & & & & * & & & & * & & & * & & * \\
\hline Turnover & * & * & * & * & & & * & * & * & & * & & * & * & * & & & * & & * & * \\
\hline Growth & & & & & & & & * & * & & & & & & * & * & & & & & \\
\hline Holiday housing & & * & * & * & * & * & & * & & & & & & * & & & & & & & * \\
\hline Amenities & & & * & * & * & * & * & & & & & & * & * & * & & & & & & * \\
\hline Urbanisation & * & * & * & & * & * & & & & & & & * & & * & & * & & * & * & * \\
\hline Specialisation & & & * & & & & & & & & & * & * & & * & * & * & * & * & * & \\
\hline Agri/Serv/FIRE & * & * & * & & * & & & & * & * & & & * & & * & * & * & * & * & * & \\
\hline Industry & & & & * & & & & & * & * & & & * & * & & * & & & * & * & * \\
\hline Participation & * & * & & & * & & & * & * & * & * & * & & * & * & * & * & & & & * \\
\hline Unemployment & & * & & & * & & * & * & & & & * & * & & * & & & & & & \\
\hline Youth unempl. & * & & & & * & * & & * & * & * & * & & & * & & * & * & * & & * & * \\
\hline Inactivity & * & * & & * & & ‡ & & & & * & * & * & * & & * & & * & & * & & \\
\hline Education & * & * & * & & & & & * & * & * & * & & * & & * & * & & * & * & * & * \\
\hline Illiteracy & * & & & & * & & & * & & * & * & & & & * & & * & & * & * & * \\
\hline Skilled & * & & * & . & & & & & * & * & * & & & & & * & & * & & * & \\
\hline Skilled manual & * & * & * & & * & & & & * & * & * & * & & & * & & & * & * & & * \\
\hline Unskilled & * & * & * & * & * & & * & * & * & & & * & * & & * & & * & * & & * & \\
\hline
\end{tabular}

Notes: Asterisks indicate chi-square statistic significant at $10 \%$.

In contrast to this picture of relative dissimilarity of patterns, the results from the chi-square analysis (Table 4) return a much wealthier set of persistence indicators (the number of significant links triples compared to Table 3). Within categories, similarity of spatial patterns is now more evident in the case of labour force characteristics, although the limited evidence of similarity in spatial patterns for characteristics of regional structure persists. Housing amenities, urbanisation and even industrial structures are now much more strongly linked to productivity and growth. Spatial patterns of incomes (GDP pc) and firm turnover (sales) are also more strongly linked to labour market 
outcomes, although surprisingly the spatial dynamics of the latter remain consistently dissimilar to those of earnings. Also surprising is the finding that spatial patterns of clustering for growth are independent to those of incomes, in contrast to the findings of Dall'erba (2003). Finally, youth unemployment appears in Table 4 to be much more closely linked to labour force characteristics, while the similarity of patterns between regional structures and some labour market outcomes and labour force characteristics also intensifies.

Obviously, the difference in the results between the two sets of analysis is not surprising. The correlation analysis is much more sensitive, as it takes into account the intensity of the spatial patterns, while the chi-square analysis does not. The latter is best suited to capture the persistence, across socio-economic aggregates, of general spatial patterns of association. For example, it tells us how consistently regions that are classified as, say, low-high in one set of socio-economic indicators appear also as low-high (or how-low, depending on measurement) clusters in terms of other socio-economic indicators. The former looks further at how persistent the intensity is of the spatial association between local and neighbouring outcomes.

To examine further the robustness of these results, we also performed a principal components analysis (PCA) on the local Moran Is obtained in the previous section. We applied five types of analysis as follows. First, we run a simple un-rotated PCA, allowing for components to be retained that had an associated eigenvalue above a threshold of 1.2. This returned six significant components. Then, we applied a principal components factor analysis allowing for obliquely rotated (non-orthogonal) components. This method was applied both to the original local Moran statistics as well as to adjusted ones (where Moran statistics with p-values below 0.333 were assigned a zero value). Again, the criterion for retained components was an eigenvalue greater than 1.2 , but in these sets of factor analysis we also restricted the results to producing only three components, to bring the resulting components closer to the classification 
of variables used earlier that split the variables into structures, incomes and outcomes. The results from these analyses are reported in Table 5.

Table 5. Similarity between spatial patterns: principal components analysis

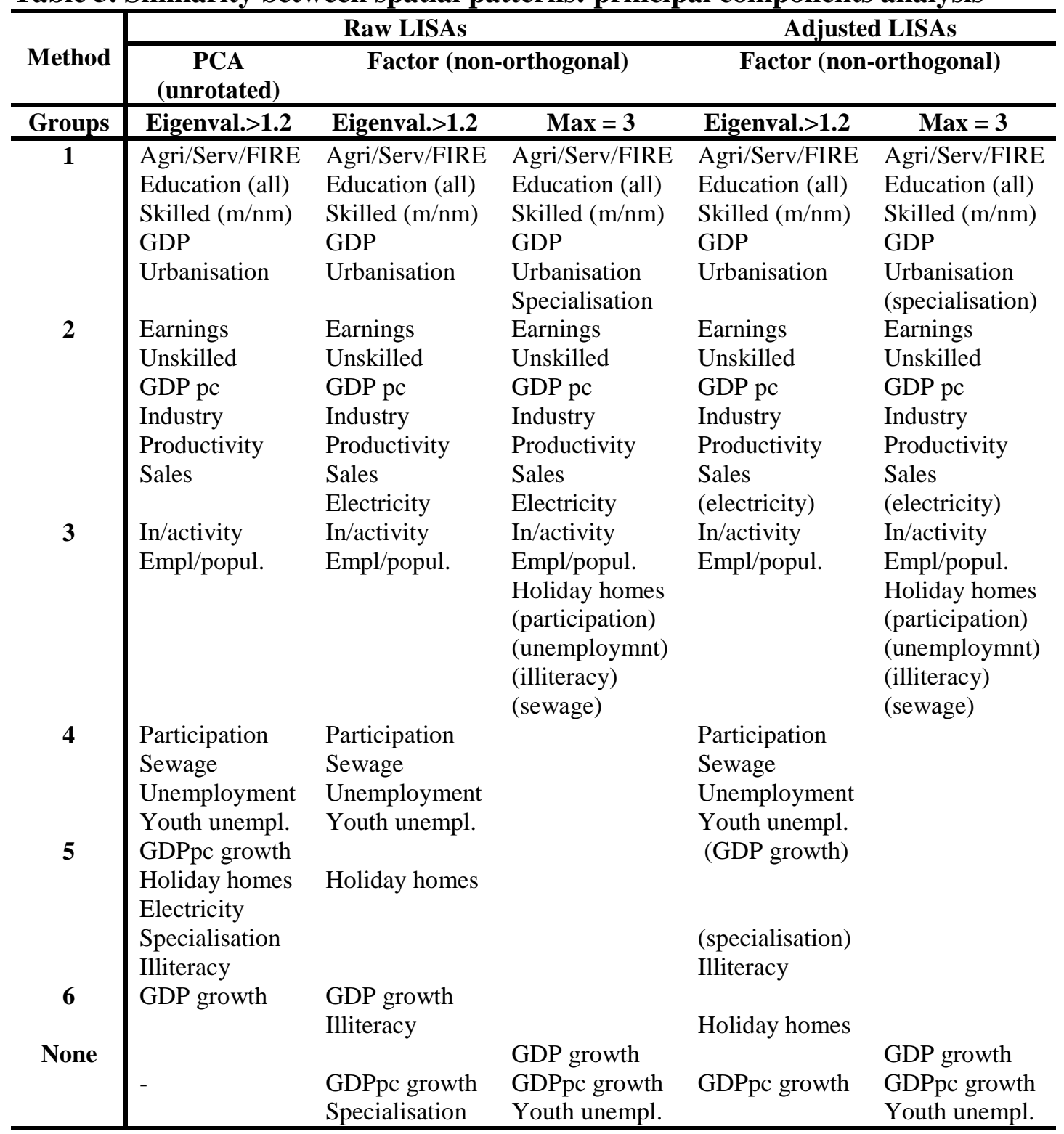

Notes: Variables classified into components according to their factor loadings. Variables in parentheses have factor loadings between 0.4 and 0.6 Variables with factor loadings below 0.4 are not classified.

As can be seen, the results for the first three components are very stable across the different methods applied. Across all analyses, the first component captures just less than $30 \%$ of total sample variability, while it takes around ten 
components to reach $90 \%$ of explained variability. The six retained components in the unrestricted analyses capture exactly $80 \%$ of this variation (around $58 \%$ for the first three components). Although it is difficult to interpret these figures as suggesting either weak or strong connectivity/similarity of spatial patterns (especially given the fact that many of the variables in the dataset are either extremely similar - e.g., activity and participation rates - or definitionally correlated - e.g., skilled and unskilled employment), the persistence of classifications of variables across groups suggests the presence of clear divisions in spatial patterns across groups of variables. Thus, it can be inferred that, also from this type of analysis, the evidence of similarity of spatial patterns across types of socio-economic aggregates (structures versus incomes versus outcomes) is particularly weak.

More specifically, the groups obtained from the principal components analyses suggest clear groupings along the lines of the classifications identified earlier in an ad hoc fashion. The first component captures mainly spatial patterns in regional structures (including key labour force characteristics), covering variables like urbanisation, GDP, education, sectoral employment compositions and skilled employment. The second component captures mainly what was described earlier as the regional incomes category, including GDP per capita, earnings, sales and productivity, as well as this time unskilled and manufacturing employment and probably household access to electricity. The third and fourth components capture the labour market outcomes group, i.e., employment participation, inactivity, unemployment and youth unemployment (as well as housing access to sewage and sometimes illiteracy). ${ }^{13}$

The last two components (fifth and sixth) are much weaker and as the analysis becomes more sensitive (relaxing the orthogonality condition and using

\footnotetext{
${ }^{13}$ The fact that the spatial patterns for these labour market variables are split into two groups (third and fourth component; although when we force the analysis to produce only three principal components they do return as a single third group) is evidence of the weak association of spatial patterns within the labour market and thus, albeit quite tentatively, of the fact that spatially-focused interventions to address one type of problems in the labour market (e.g., inactivity) will not automatically spill-over to addressing other types of problems (e.g., unemployment) in the same spatial micro-systems.
} 
adjusted Moran Is) the elements appearing in these two groups are either absorbed in the third component or dropped as outliers (not belonging to any of the retained components).

In trying to combine all the information derived from these three sets of analysis, it appears that a single inference that will be consistent with all these results can in fact be drawn: in addition to their 'multiple geographies' in terms of the spatial distribution of socio-economic characteristics and outcomes, the Greek regions do not present a singular geography also in the case of spatial linkages. The principal components analysis suggests that there are at least six principal spatial patterns characterising the variables examined in this study and that, moreover, they can hardly be reduced to anything less than three very distinct components, even when we force the data to do so (and allow for oblique rotation of components).

The evidence from the other two pieces of analysis is probably even more telling. Even combining the results of the correlation and chi-square analyses, in almost half of the cases of all possible pairs of socio-economic aggregates there is no consistency across the regions in their spatial dynamics. Moreover, persistence / similarity of spatial dynamics is weakest in the areas where one would expect to find the strongest links, namely in the interaction between labour force characteristics and labour market outcomes (where evidence of similarity is found in only $40 \%$ of the cases) and, somewhat less, between those two and regional incomes. In light of these results, it is reasonable to conclude, albeit rather tentatively, that the nature of spatial dynamics in the country is also complex and multi-faceted, as is the nature of spatial disparities. This adds yet another dimension to the complexity of what we labelled here as the 'regional problem of Greece'. 


\section{Conclusions}

In many respects Greece presents a rather peculiar case of economic geography. The country has a long and turbulent political history, which is marked not only in the culture of its population but, interestingly, also in the patterns of disparity and spatial association across its regions. The influences of this political history are expressed in various ways, but two observations suffice to highlight the point: the over-concentration of population and financial capital in Athens and the surprising north-south divide in terms of housing amenities. Further, other factors have played a significant role in influencing the socio-economic geography of the country. The prolonged experience of relative national underdevelopment has had a negative impact on the development of the most peripheral regions and especially on the physical and economic connectedness of these regions to the economic and political core. Some times this disadvantage of peripherality has been reinforced by the international relations of the country: sustained episodes of hostility with Greece's neighbours have impacted adversely on the developmental potential of the Greek periphery, especially in the cases of northwest Greece, East Macedonia and Thrace, and parts of the eastern Aegean.

This paper undertook a detailed exploratory spatial data analysis and through a thorough examination of the patterns of clustering, spatial competition and heterogeneity it was able to trace much of this history into the contemporary patterns of inequality and the spatial dynamics connecting the regions of Greece. The analysis showed that regional disparities in Greece are largely masked by the complexity of its socio-economic geography. Thus, while at the aggregate level inequalities appear to be modest according to European and OECD standards, at closer inspection the differences across regions, especially in terms of economic structures, appear much more sizeable. Through the examination of a large set of socio-economic variables we were able to picture the pattern of 'multiple geographies' in the country, which combines elements of north-south, east-west, core-periphery and rural-urban dichotomies. This 
spatial heterogeneity seems to be related further to a second-level characteristic, which has detrimental effects on the developmental potential of the country at large: despite the evidence of relatively strong positive spatial dependence at the aggregate level, Greece lacks a diffused distribution of clusters that could function as growth poles/centres for regional and national economic development. Rather, the spatial dynamics examined seem to follow and to reproduce the fragmentation and heterogeneity of Greece's economic space. Thus, in most of the cases, exploratory spatial data analysis only reveals a single centre of high-high outcomes, often located in or around the Capital.

At a first reading, this problem is not dissimilar to that of other western European countries. In the UK, this problem, emphatically represented by the well-studied north-south divide, is being addressed through administrative devolution and the support of a clusters-based industrial policy, which aims at creating growth clusters across the more backward areas of the country (mainly areas of industrial decline) (DTI, 1998). In Ireland, similar issues are being addressed with the design of a spatial planning policy that promotes the emergence of developmental hubs and corridors (NSS, 2002). In Greece such ambitious policy measures are far from being discussed, let alone designed and implemented. The country relies heavily on the EU Structural Funds for the conduct of its regional policy. It is believed that the exploratory spatial analysis undertaken here, by revealing the relative dissimilarity of spatial patterns and thus the heterogeneity of spatial problems and needs in the various parts of the country, has helped highlight the limitations of simple redistribution measures in addressing the problems of backwardness and disparity of the Greek regions. These problems appear to be well rooted to the political and economic history of the country and they clearly take the form of complex heterogeneity and weak localised spatial spillovers. In these circumstances, it appears necessary for policy to focus on interventions that will address exactly the causes of this multiple heterogeneity, than on ones that rely on redistributing resources from better-off areas to poorer ones. 
The analysis of the last section, which examined the persistency of the revealed spatial processes across a range of socio-economic indicators, reinforces this point by showing that spatial connectedness (in the form of dependence/autocorrelation rather than heterogeneity) is not only weak but, more importantly, not consistent across indicators. The implication of this is that spatial processes that operate in the context of income formation (GDP pc, earnings, etc) do not overlap with those of human capital formation (education, skills, etc) or of labour market outcomes (e.g., unemployment). Although this is not necessarily a feature unique to Greece (indeed, it is important to replicate this analysis for other countries, in order to examine how deviant the results for Greece are in comparison to some universal 'norm'), it represents clearly another dimension of Greece's developmental problem. To the extent that spatial spillovers in the labour market, however small, do not link to similar processes in income formation, it appears that policy intervention is required in all fields of social activity. In other words, the lack of similarity in the spatial patterns revealed in the analysis of the previous section presents a limitation for social and economic policy in Greece to exploit policy spillovers and complementarities and thus to address complex and multifaceted problems with targeted overarching policies.

Of course, the validity of this conclusion is to a large extent conditioned on the validity of the approach employed, to compare patterns of spatial association across different sets of socio-economic indicators. Replication of this work in other datasets and contexts and, maybe most importantly, subsidiary analysis of the same data using alternative pattern-comparison techniques (e.g., patternmatching in GIS) are considered necessary before firm conclusions can be drawn not only about the role of policy in addressing issues of regional imbalance, but basically about the interpretation of the obtained results that was advanced here. It is hoped that research into the issue will continue, following the present analysis. 


\section{References}

Anselin L. (1988), Spatial Econometrics: methods and models, Kluwert Academic Publishers.

Anselin L. (1995), Local indicators of spatial association - LISA, Geographical Analysis 27, pp.93-115.

Alexiadis S. and Tomkins J. (2004), Convergence clubs in the regions of Greece, Applied Economics Letters 11, pp.387-391.

Blackaby D. and Murphy P. (1995), Earnings, unemployment and Britain's North-South divide: real or imaginary?, Oxford Bulletin of Economics and Statistics 57, pp.487-512.

Christopoulos D. and Tsionas E. (2004), Convergence and regional productivity differences: evidence from Greek prefectures, Annals of Regional Science 38, pp.387-396.

Dall'erba S. (2003), Distribution of regional income and regional funds in Europe, 1989-1999: an exploratory spatial data analysis, REAL Discussion Paper 03/01, Regional Economics Applications Laboratory, Chicago.

DTI (1998), Our Competitive Future - Building the Knowledge Driven Economy, White Paper on Competitiveness, HMSO, London.

Duranton, G. and Monastiriotis V. (2002), Mind the Gap: the Evolution of Regional Earnings Inequalities in the UK, 1982-1997, Journal of Regional Science 42 (2), pp.219-256.

EC (1999), European Spatial Development Perspective: towards balanced and sustainable development of the territory of the European Union, Committee on Spatial Development, Office For Official Publications of the European Communities, Luxemburg.

EC (2005), Regions: Statistical Yearbook 2005, Office For Official Publications of the European Communities, Luxemburg.

Farsari Y., Prastacos P. and Manioudakis N. (2001), Demographic and social characteristics of the labor market in the Greek regions, pp.497-512 in B. Kotzamanis and V. Pappas (eds) Spatial Dimensions of Demographic Events, Thessaly University Press [in Greek]. 
Hagen A. (2003), Fuzzy set approach to assessing similarity of categorical maps, International Journal of Geographical Information Science 17(3), pp.235-249.

Kamarianakis Y. and Prastacos P. (2001), Classification of the municipalities of Greece according to their socio-economic characteristics, pp.187-208 in B. Kotzamanis and V. Pappas (eds) Spatial Dimensions of Demographic Events, Thessaly University Press.

Kamarianakis Y. and Kontos D. (2004), Classification of Greek Municipalities According to the Socioeconomic Characteristics, paper presented at the Young Researchers Meeting of the HellasGIS Association, National Polytechnic School of Athens [in Greek].

Kaminski B. and de la Rocha M. (2003), SAP in the Balkans: integration options and their assessment, World Bank Policy Research Working Paper No3108, World Bank

Konsolas N., Papadaskalopoulos A. and Plaskovitis I. (2002), Regional Development in Greece, Springer, Berlin.

Labrianidis L. (2003), Delocalisation of labour intensive industries, ch.11 in G. Petrakos and P. Liargovas (eds), Regional Development and Cross-border Cooperation in SEE, SEED, Thessaly University Press, Greece.

Lucas R. (1988), On the mechanics of economic development, Journal of Monetary Economics 22 (1), pp.3-42.

Lyberaki A. (2004), The Greek tessera (NAPE) in the European jigsaw: intervention tool or auto-pilot?, mimeo, Panteion University, Athens [in Greek]

Monastiriotis V. (2005), Geographical and Political Economy Perspectives on Regional Disparities in Greece, mimeo, Hellenic Observatory, LSE, London.

Monastiriotis V. (2006), Sub-Regional Disparities in Britain: convergence, asymmetries and spatial dependence, Research Papers in Environmental and Spatial Analysis No112, Department of Geography and Environment, LSE.

NSS (2002), National Spatial Strategy for Ireland 2002-2020, Government Publications, Stationary Office, Dublin.

Ottaviano G. and Puga D. (1997), Agglomeration in the Global Economy: A Survey of the 'New Economic Geography', CEPR Discussion Paper 1699, Centre for Economic Policy Research, London. 
Petrakos G. (2001), Patterns of regional inequality in transition economies, European Planning Studies 9 (3), pp.359-383

Petrakos G. and Brada J. (1989), Metropolitan concentration in developing countries, Kyklos 42 (4), pp.557-578.

Petrakos G. and Psycharis Y. (2004), Regional Development in Greece, Kritiki Publishers [in Greek]

Petrakos G. and Saratsis Y. (1997), Regional inequalities and spatial specialisation in Greece, in A. Kindis (ed), The Present and Future of the Greek Economy, Vol.B, pp. 449-476. Athens: Athens University of Economics and Business-Gutenberg [in Greek].

Petrakos G. and Saratsis Y. (2000), Regional inequalities in Greece, Papers in Regional Science 79, pp.57-74.

Poti B. and Basile R. (2000), Differences in innovation performance between advanced and backward regions in Italy: the role of firms' strategies, organizational factors and institutions, Report for the CONVERGENCE Project, TSER Programme, EC DGXII (available at http://pascal.iseg.utl.pt/ converge/pdfs/(24).pdf)

Sokal R. and Menozzi P. (1982), Spatial autocorrelation of HLA frequencies in Europe, American Naturalist 119, pp.1-17.

Siriopoulos C. and Asteriou D. (1998), Testing for convergence across the Greek regions, Regional Studies 32, pp.537-46.

Wartenberg D. (1985), Multivariate spatial correlation: a method for exploratory geographical analysis, Geographical Analysis 17 (4), pp.263283. 




\section{Other papers from the Hellenic Observatory}

23. Klarevas Louis, Greeks Bearing Consensus: An Outline for Increasing Greece's Soft Power in the West Hellenic Observatory Discussion Paper No 18, Hellenic Observatory, LSE, September 2004

22. Koutalakis Charalampos, Environmental Harmonization in Central Eastern Europe: Lessons from the Southern Enlargement E-Paper No4, Hellenic Observatory, July 2004

21. Kamaras Antonis, Market Reforms and Urban Disparity: the cases of Athens and Thessaloniki E-Paper No 3, Hellenic Observatory, LSE, July 2004

20. Sotiropoulos Dimitri A., Democratization, Administrative Reform and the State in Greece, Italy, Portugal and Spain: Is There a 'model' of South European Bureaucracy? Hellenic Observatory Discussion Paper No17, Hellenic Observatory, LSE, April 2004

19. Sotiropoulos Dimitri A., Formal Weakness and Informal Strength: Civil Society in Contemporary Greece Hellenic Observatory Discussion Paper No16, Hellenic Observatory, LSE, February 2004

18. Klarevas Louis, The Eagle and the Phoenix: The United States and the Greek Coup of 1967 Hellenic Observatory Discussion Paper No 15, Hellenic Observatory, LSE, January 2004

17. Papaspyrou Theodoros, EMU strategies: Lessons from Greece in view of the EU

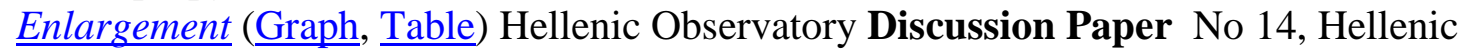
Observatory, LSE, January 2004

16. Papadimitriou Dimitris, The limits of engineering collective escape: the 2000 reform of the Greek labour market Hellenic Observatory Discussion Paper No13, Hellenic Observatory, LSE, October 2003 (also published as Hellenic Observatory Epaper No2)

15. Featherstone Kevin, The Politics of Pension Reform in Greece: modernization defeated by gridlock Hellenic Observatory Discussion Paper No12, Hellenic Observatory, LSE, October 2003 (also published as Hellenic Observatory E-paper Nol)

14. Stavridis Stelios, Assessing the views of academics in Greece on the Europeanisation of Greek foreign policy: a critical appraisal and a research agenda proposal, Hellenic Observatory Discussion Paper No11, Hellenic Observatory, LSE, September 2003

13. Stavridis Stelios, The Europeanisation of Greek Foreign Policy: A Literature

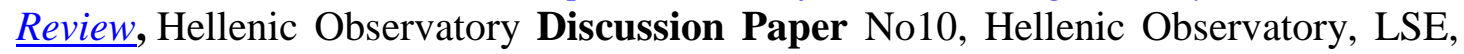
September 2003 
12. Bratsis Peter, The Constitution of the Greek-Americans, Hellenic Observatory Discussion Paper No9, Hellenic Observatory, LSE, August 2003

11. Bratsis Peter, Corrupt Compared to What? Greece, Capitalist Interests, and the Specular Purity of the State Hellenic Observatory Discussion Paper No8, Hellenic Observatory, LSE, August 2003

10. Anastasakis Othon and Bojicic-Dzelilovic Vesna Balkan Regional Cooperation \& European Integration Hellenic Observatory Policy Paper No2, Hellenic Observatory, LSE, July 2002

9. Stavrakakis Yannis, Religion and Populism: Reflections on the 'politicised' discourse of the Greek Church Hellenic Observatory Discussion Paper No7, Hellenic Observatory, LSE, May 2002

8. Stefanidis Ioannis D., Pressure Groups and Greek Foreign Policy, 1945-67 Hellenic Observatory Discussion Paper No6, Hellenic Observatory, LSE, December 2001

7. Tsoukalis Loukas (ed.) Globalisation \& Regionalism: A double Challenge For Greece Hellenic Foundation for European \& Foreign Policy (ELIAMEP), Athens 2001 (hard-copy only, available upon request; please post a cheque of $£ 10$ payable to "LSE" to: The Hellenic Observatory, European Institute, LSE, Houghton Street, London WC2A 2AE, UK)

6. Woodward Susan L., Milosevic Who? Origins of the New Balkans Hellenic Observatory Discussion Paper No5, Hellenic Observatory, LSE, July 2001

5. Kamaras Antonis, A Capitalist Diaspora: The Greeks in the Balkans Hellenic Observatory Discussion Paper No4, Hellenic Observatory, LSE, June 2001

4. Anastasakis Othon, Extreme Right in Europe: A Comparative Study of Recent Trends Hellenic Observatory Discussion Paper No3, Hellenic Observatory, LSE, November 2000

3. Holm Erik, High Politics and European Integration: From EMU to CFSP Hellenic Observatory Discussion Paper No2, Hellenic Observatory, LSE, November 2000

2. Rozakis Christos, The Protection of Human Rights in Europe: Evolving Trends and Prospects Hellenic Observatory Discussion Paper No1, Hellenic Observatory, LSE, October 2000

1. Gligorov, V., Kaldor, M., and Tsoukalis, L. Balkan Reconstruction and European Integration Hellenic Observatory Policy Paper No1 (jointly with the Centre for the Study of Global Governance, LSE and the Vienna Institute for International Economic Studies), October 1999 